\title{
MI LENGUA MATERNA Y YO
}

\author{
Franklin Perry Price
}

\begin{abstract}
RESUMEN
En este texto, se presenta una reflexión acerca del criollo limonense y cómo esta lengua ha sido percibida por hablantes de otras lenguas en espacios como el aula escolar. Además, ante el planteamiento de la posible desaparición del criollo limonense, se enumeran varios argumentos que apuntan hacia lo contrario, por ejemplo, la investigación lingüística de esta lengua, el uso cotidiano en diferentes contextos, inserción laboral y, quizás lo más importante, también se habla en otros lugares y no solo en Limón.
\end{abstract}

Palabras clave: lingüística, criollo limonense, contextos de habla, continuidad de la lengua.

\begin{abstract}
This article presents a reflection of Limonese Creole and how speakers of other languages have perceived its use in domains of usage like the academic classroom. In addition, considering the possible disappearance of Limonese Creole, the author enumerates arguments to the contrary, for example, the ongoing linguistic study of this language, its daily use in differing contexts by its speakers, employment and, maybe the most important, that fact that it is used in other places and not solely in Limon.
\end{abstract}

Key words: linguistics, Limonese Creole, domains of usage, language maintenance.

Durante la última semana de octubre 2011, la Escuela de Filología, Lingüística y Literatura de la Facultad de Letras de la Universidad de Costa Rica se dedicó a celebrar la diversidad lingüística de Costa Rica. El evento estuvo dedicado al doctor Adolfo Constenla, amado profesor e incansable investigador de las lenguas indígenas nuestras.

La preocupación general pareció girar en torno del futuro de estas lenguas en el territorio nacional. Parece, por los discursos escuchados, que esa riqueza de comunicación oral desaparecerá si no se hace algo para asegurar su permanencia.

Lic. Franklin Perry Price. Profesor jubilado.

Recepción: 12- 03- 2012

Aceptación: 17- 04- 2012 
Y no es que nada se haya hecho, porque ya se han ido aquellos días cuando se negaba el carácter pluriétnico y multilingüístico de nuestra patria. Mario Portilla, Adolfo Constenla, Marva Spence, Anita Herzfeld, entre otros, han sido investigadores asiduos que han levantado voces y plumas en defensa de estas lenguas. Interesante fue observar que incluyeran un día para el LESCO (lengua de señas costarricense).

El lunes 24 fue dedicado al criollo limonense. Convocados a un conversatorio, como hablantes nativos fuimos Kathleen Sawyers y yo, presididos por la doctora Herzfeld. Entre los asistentes se encontraban Ronald Ross, Jeanina Umaña, Dorothy Mosby, Adolfo Constenla, Vallerie Burke, María Eugenia Bozzoli, Ignacia Santos, Carlos Sánchez, entre otros. Las siguientes palabras fueron mi contribución:

Tal vez no debería decir esto, pero lo voy a decir de todas maneras. Tengo una relación agridulce con mi "lengua materna" porque, pensándolo bien, quizás nunca tuve una.

Y la verdad es que mi madre me hablaba en una lengua que ahora los lingüistas llaman criollo limonense y los vallecentralinos llaman mekatelyu, la comunidad y mi madre llamaban inglés y las señoras de la elite de Limón llamaban Bad English o Broken English, estigma incluido.

Esas mismas señoras, y también en la iglesia, me hablaban en un inglés victoriano, anacrónico, desplazado, anticuado y con mucha influencia de la Biblia, versión King James. Los vecinos, por otra parte, me hablaban en una extraña jerigonza que ellos llamaban castellano. Años después, como dijo Delia MC Donald, "me encontraría la escuela", en donde mi maestra, la niña Abelina Oreas, me dijo que mi lengua materna era el español, sinónimo de castellano. Atónito -y no dramatizo aquí-, asombrado, sobrecogido quedé cuando Don Elean Guerrero, Trimurti Matarrita, Rosivett González, Boanerjes, Argentina Quevedo me hicieron comprender que aquella jerigonza aullante en que se comunicaban mis vecinos era mi lengua materna y que no debía hablar más eso que ustedes llaman inglés.

Fernando Carrión Carvajal me dictaba los nombres de mis primos Javier y Jaime; yo transcribía Avier y Aime sin las jotas aspiradas, puesto que en mi "lengua materna" no se usaba la jota aspirada. Y aunque en el dialecto de prestigio del inglés la hache se aspira casi como la jota del español, no lo hacíamos tampoco. En cambio, mis tías sí la pronunciaban donde no debía ir: decían heg en lugar de egg para huevo en inglés y ham en vez de am para soy. También, don Fernando me dictaba los nombres de otras de mis primas: Sonia y yo escribía Soña; Kenia y yo escribía Keña. Mis párrafos dictados, por consiguiente, eran un desastre y mis maestros, brazos en alto, exclamaban: "No sé qué hacer; estos negros no tienen ortografía".

Luego Mayra Herra, una filóloga muy estimada, me diría que los negros de la segunda generación solíamos nasalizarlo todo. Y qué decir del género de los pronombres cuando nos alejamos mucho del antecedente. También, aprendería de Eulalia Bernard que los negros de la segunda generación hablamos una versión africanizada de las lenguas europeas, y no tiene nada que ver con abejas, cuando no las subvertimos a propósito. Lo de hablar por la nariz, como decimos en Limón, me parece muy interesante porque, según afirma Bernal William, anda una teoría por ahí que sostiene que la gente cuando está enamorada suele nasalizarlo todo. Entonces, como diría Descartes, los negros vivimos en un eterno estado de enamoramiento.

En cuanto a su subsistencia como herramienta importante de comunicación, prácticamente en su totalidad, los expertos en criollística y otros estudiosos aseguran que 
el criollo limonense tiene sus días contados. Entre otros, Jack Wilson y Fernando Wright (que de Dios gocen), Ronald Ross, Marva Spence, Mario Portilla, Elizabeth Grace Winkler, Bernald Williams, Kathleen Sawyers, Anita Herzfeld. Creo que solamente Eulalia Bernard y yo sostenemos que el criollo limonense is going nowhere. It's here to stay. Tanto el doctor Mario Portilla como la doctora Anita Herzfeld, ambos entrañables amigos míos, incansables investigadores en el campo, en conversaciones privadas comigo, que yo ahora hago públicas, en resumen, han dicho que tengo una relación romántica e idealizada con la lengua y eso me impide visualizar la realidad. Y es por eso que no me doy cuenta "por quién doblan las campanas". Con el perdón de John Donne y Ernest Hemingway.

Yo a eso diría que no, porque en realidad a mí ni me perjudica ni me beneficia la permanencia o desaparición del criollo limonense. Este criollo fue vital para la vida de nuestra comunidad, la construcción del ferrocarril, la construcción y operación de los muelles, la industria bananera, etc., etc. Que conste aquí que no soy lingüista y hablo como uno que simplemente ha tenido experiencia con la lengua en cuestión. Ahora, si ya se ha agotado la vida útil de esta lengua, que se vaya. Yo poseo otras dos lenguas. Ambas prestadas, que hoy por hoy cubren mis necesidades básicas de comunicación y hasta me atrevo a escribir en ellas. A saber, el inglés y el español. Gabriel Vargas, otro filólogo, defensor incansable de las lenguas y amigo entrañable, critica mi posición y entre otras cosas dice que con la muerte de una lengua desaparece una cultura, una manera de pensar y por ende de ver el mundo. Otra joven relacionada a una institución que promociona y protege lenguas "minoritarias" en Costa Rica me dijo que se sorprendía del hecho de que nunca los negros les habíamos solicitado que se incluyera la enseñanza de nuestro criollo en el sistema educativo del país.

Ahora ustedes se preguntaran por qué soy tan obcecado con la idea de que la lengua no desaparece. Pues hay varias razones. Entre otras, las siguientes:

a. Encuentros como este (semana dedicada a las lenguas autóctonas y criolla de Costa Rica).

b. La investigación y difusión que han hecho los expertos, por ejemplo: Anita, en gramática, entre otros aspectos; Mario, en lexicografía; Marva, en sociolinguiística; la poesía de Marcia Reid y de Eulalia en criollo, que no solamente escriben sino que también declaman; Carol Britton, que publica un libro de los cuentos de Ananacy en inglés, español y criollo y que también se cuentan a niños.

c. El aumento de su prestigio al emplearlo para las letras del calypso, el reggae, el reguetón, el rap y por ende su difusión entre los jóvenes, lo cual significa relevo y continuidad.

d. El hecho de que se usa entre negros como lengua de intimidad, familiar, de confianza.

e. El que los caucásicos de Limón lo estén utilizando y que todos lo entiendan.

f. El que se haya enriquecido con integraciones, calcos y préstamos del Español.

g. El asunto de la diglosia y la poliglosia (bilingüismo, polilingüismo donde una de las lenguas es la de prestigio).

h. Quizás el más importante es el hecho que no solamente en Limón se habla sino que en todos los países que otrora fueran colonias, enclaves, o zona de influencia británica se habla una variante y es como una especie de lingua franca. 
i. El asunto del continiuum.

j. $\quad$ Ahora que se han puesto de moda los infames call centers, el criollo ha recobrado terreno entre los jóvenes, porque siempre será más fácil ir del criollo al inglés estándar que del español al inglés estándar. El criollo, según Mario Portilla, tiene alrededor de un $98 \%$ de vocabulario inglés. 